
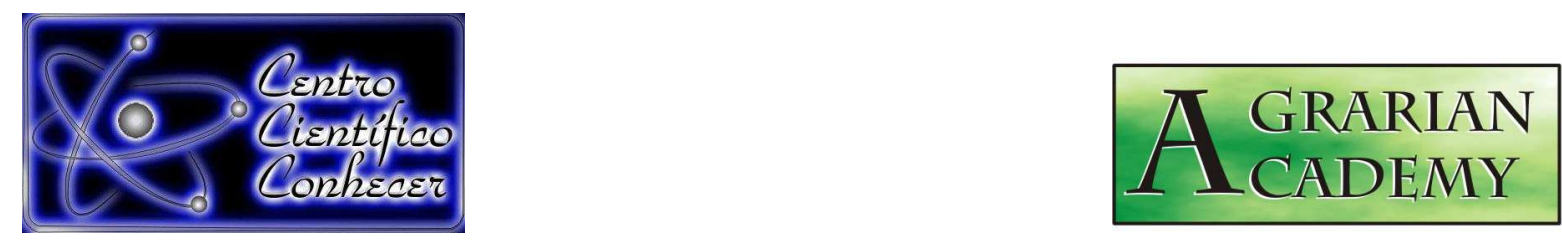

\title{
CARACTERIZAÇÃO QUÍMICA, FÍSICA E ELEMENTAR DE SUBSTRATOS ORIUNDOS DA MINERAÇÃO DE FERRO EM CONCEIÇÃO DO MATO DENTRO - MG
}

\footnotetext{
$\underline{\text { Rodrigo de Oliveira Lara }}{ }^{1}$, Israel Marinho Pereira ${ }^{2}$, Michele Aparecida Pereira da Silva ${ }^{3}$

${ }^{1}$ Mestre do Departamento de Engenharia Florestal da Universidade Federal dos Vales do Jequitinhonha e Mucuri (rodrigolara1987@hotmail.com), Diamantina-Brasil.

${ }^{2}$ Professor Doutor do Departamento de Engenharia Florestal da Universidade Federal dos Vales do Jequitinhonha e Mucuri-UFVJM

${ }^{3}$ Pós-doutoranda do Departamento de Engenharia Florestal da Universidade Federal dos Vales do Jequitinhonha e Mucuri- UFVJM
}

Recebido em: 30/11/2017 - Aprovado em: 15/12/2017 - Publicado em: 31/12/2017 DOI: 10.18677/Agrarian Academy 2017b10

\section{RESUMO}

O presente estudo teve como objetivo avaliar a composição física, química e mineralógica de diferentes materiais resultantes da mineração de ferro. Foram coletados dois tipos de substratos presentes em uma área de mineração de ferro em Conceição do Mato Dentro (MG). Procedeu-se as análises de: granulometria, densidade, porosidade, tensão e capacidade de retenção de água, químicas e elementares. Como resultado pode-se afirmar que ambos os substratos apresentam baixa capacidade de retenção de água, sendo propensos ao selamento superficial devido a quantidade de silte presente, o que pode ocasionar problemas de estresse hídrico em mudas e erosão em sulcos afetando o desenvolvimento das plantas na revegetação. As análises químicas indicaram que há necessidade de correção dos substratos, devido aos baixos teores de macronutrientes presentes nos mesmos. Também deve-se observar que os substratos apresentam elevados teores de ferro 0 que pode causar problemas no desenvolvimento inicial de mudas no estabelecimento da vegetação neste substrato. A correção da acidez e adubação do substrato promoverá 0 desenvolvimento inicial de mudas facilitando 0 estabelecimento da vegetação.

PALAVRAS-CHAVE: Filito, Petroplintita, Ray X, Serra do Espinhaço

\section{SUBSTRATES DERIVED FROM THE IRON ORE MINING FOR RECOVERY PURPOSES OF DEGRADED SITES}

\footnotetext{
ABSTRACT

The present study aimed to evaluate the physical, chemical and mineralogical composition of different materials resulting from iron mining. Two types of substrates

AGRARIAN ACADEMY, Centro Científico Conhecer - Goiânia, v.4, n.8; p.93 2017
} 
were collected in an area of iron mining in Conceição do Mato Dentro (MG). The analyzes were: granulometry, density, porosity, tension and water retention capacity, chemical and elemental. As a result, it can be stated that both substrates have low water retention capacity, being prone to surface sealing due to the amount of silt present, which can cause problems of water stress in seedlings and erosion in grooves affecting the development of plants in the soil revegetation. The chemical analysis indicated that there is a need for correction of the substrates, due to the low macronutrient contents present in them. It should also be noted that the substrates have high levels of iron, which can cause problems in the initial development of seedlings in the vegetation establishment in this substrate. Correction of acidity and fertilization of the substrate will promote the initial development of seedlings, facilitating the establishment of vegetation.

KEYWORDS: Petroplinthite, Ray X, phylite, Serra do Espinhaço

\section{INTRODUÇÃO}

A mineração de ferro no Estado de Minas Gerais destaca-se economicamente, principalmente na região do Quadrilátero Ferrífero, apesar de causar grande impacto ambiental decorrente da remoção da cobertura vegetal e das camadas superficiais do solo. O governo, assim como a sociedade, tem mostrado interesse e preocupação crescente com a proteção, conservação e qualidade do meio ambiente, criando novas diretrizes para a indústria minerária. A restauração florestal das áreas mineradas, entre outras, tornou-se, então, uma condicionante indispensável no licenciamento das minas (FERREIRA, 2011).

Ambientes perturbados por mineração são peculiares por apresentarem características edáficas típicas de substratos exauridos, porém com resguardo parcial das propriedades físicas, assim é necessário proceder a restauração (VIANA et al., 2012). Esse processo de restauração geralmente é lento e depende da oferta de propágulos advindos de atributos ambientais. Conhecer os parâmetros que interferem na capacidade de restauração dos ecossistemas perturbados pode ser fundamental para definir estratégias objetivas de restauração (FIGUEIREDO et al., 2011).

Um dos objetivos das técnicas de restauração florestal é o aproveitamento do potencial de resiliência (auto-regeneração) das áreas a serem recuperadas e da máxima quantidade e diversidade de material vegetal (propágulos e restos vegetais) disponível em áreas cujo licenciamento ambiental para atividades de mineração, represamento de cursos d'água e outros em que a vegetação seja suprimida (MIRANDA NETO et al., 2012).

Considerando que a exploração de recursos minerais está regulamentada na legislação brasileira e que deve ser feita segundo critérios definidos no processo de licenciamento ambiental, conforme consta na Resolução do Conselho Nacional de meio Ambiente - CONAMA n. 237 de 1997, as empresas mineradoras que possuem a licença de lavra têm por obrigação recuperar a área degradada pela mineração. Essa obrigação advém da necessidade de retenção de solo, contenção de erosão, manutenção da biodiversidade e da beleza cênica, sendo o plantio de mudas indicado para locais onde além da cobertura vegetal, foram também eliminados os meios de regeneração natural, como o banco de sementes, de plântulas, chuva de sementes e possibilidade de rebrota (FELFILI et al., 2008).

A caracterização de minérios é uma etapa fundamental para o aproveitamento de um recurso mineral de forma otimizada, pois fornece ao engenheiro os subsídios mineralógicos e texturais necessários ao correto 
dimensionamento da rota de processo, otimizando o rendimento global de uma planta. A caracterização permite a determinação de propriedades físicas e químicas de minérios atingindo, de acordo com a aplicação, uma otimização da qualidade com o menor custo associado (NEUMANN et al., 2004).

Nos trabalhos executados com o objetivo de recuperar áreas degradadas pela mineração, por meio de processos de revegetação, é de grande importância o conhecimento das características químicas, físicas e mineralógicas dos materiais que irão ser utilizados como substrato para o crescimento e desenvolvimento das plantas. Para isso, devem ser identificadas previamente as características benéficas e, ou, aquelas adversas para essas plantas (SILVA et al., 2006, SILVA et al., 2016).

Existe uma designação particular para materiais que podem vir a ser utilizados como substrato para a revegetação da área sob influência da mineração. São chamados "estéreis da mina" os materiais (solo, subsolo, rocha) que ocorrem naturalmente na área, não aproveitáveis economicamente, dispostos em camadas horizontais ou inclinadas, como corpos irregulares - ambos encaixados ou intimamente ligados ao minério (SILVA et al., 2006). Há também o chamado rejeito da mineração, que é o material proveniente do beneficiamento do minério de ferro, do qual já foi retirada a parte economicamente importante. Este rejeito pode estar na forma de fragmentos ou partículas secas, ou em via aquosa sendo isto dependente do tipo de beneficiamento do minério (GOMES et al., 2011).

Dependendo das características física, química e mineralógica do material, obtidas por meio de uma caracterização específica, pode-se ter uma noção das medidas ou tratamentos adequados dos substratos quando pretende-se estabelecer uma recomposição da cobertura vegetal. Dessa forma, o presente estudo teve como objetivo avaliar a composição física, química e mineralógica de diferentes materiais resultantes da mineração de ferro, visando gerar protocolo de tratamento do mesmo para facilitar o estabelecimento da cobertura vegetal durante o processo de recuperação de áreas degradadas de mineração de ferro.

\section{Área de estudo:}

\section{MATERIAL E MÉTODOS}

A área de estudo encontra-se situada nas coordenadas $19^{\circ} 02^{\prime} 04.17^{\prime \prime S}$, $43^{\circ} 25^{\prime} 22.27^{\prime \prime}$ localizada na borda leste de um conjunto de terras altas, com direção aproximada norte-sul, denominada Serra do Espinhaço. Esta região em estudo encontra-se localizada em região de clima tropical $\mathrm{Cw}$, dotada de elevada incidência de radiação solar à superfície, elevado número potencial de horas de insolação mensais e anuais e cujas temperaturas médias superam a marca dos $20^{\circ} \mathrm{C}$.

A média pluviométrica ao longo do ano é de 1.521,3 $\mathrm{mm}$, que por sua vez é marcado por grande variação estacional (um período seco e chuvoso). Os meses mais chuvosos estendem-se de outubro a março, e os meses de abril e setembro são de transição entre um regime e outro. O semestre de abril a setembro é marcado pela estação seca na região, contudo, devido à dinâmica atmosférica e a ação de vários elementos interagindo e alterando está dinâmica, tanto a estação seca quanto a chuvosa podem prolongar-se ou sofrerem atrasos.

Os substratos foram coletados na cava da mina pertencente à empresa Anglo American Ferrous, em Conceição do Mato Dentro, MG. A coleta foi feita em vários pontos das pilhas dos materiais, porém o material que não estava disposto em pilhas foi coletado in situ, em perfis de solo. A área de mineração se apresenta com geologia variada, que vai desde quartzito, itabiritos, xisto até rochas basais, hematitas e cangas. A área de coleta do substrato 1 apresenta-se com geologia de 
xistos em áreas de topo e filitos prateados. A área de coleta do substrato 2 apresenta-se composta por: áreas de canga, rochas hemáticas, quartzitos, xistos e itabiritos fragmentados.

As amostras foram coletadas em diferentes pontos de acordo com o tipo de material presente. O material coletado foi composto de três tipos diferentes de estéreis da mina que, para identificação, foram denominados substrato 1, substrato 2 e saprolito. Assim caracterizados: a) Substrato 1: rocha metamórfica, já em avançado estado de intemperismo, encontrada com frequência na área da mina. $O$ material apresenta coloração acinzentada e quando manuseado, desagrega-se com facilidade, tornando-se um pó fino; b) Substrato 2: material edafizado, de coloração vermelho, encontrado na área sob influencia da mineração, contendo grande quantidade de petroplintita na fração cascalho. Apresenta profundidade efetiva em torno de $10 \mathrm{~cm}$ e logo abaixo dessa camada são encontrados grandes blocos de "canga". A cobertura vegetal original no local de coleta eram extensões de mata e candeal e c) Saprolito: rocha metamórfica muito intemperizada, encontrada junto ao minério de ferro. Apresenta textura e composição variada conforme a rocha de origem.

Para o substrato1 (S1) e substrato 2 (S2) foram coletados 10 amostras simples para formar uma amostra composta, sendo feito no total seis coletas compostas. A coleta do saprolito foi feita em perfil de solo, sendo coletado com auxílio de uma pá e picareta. Todo material coletado foi acondicionado em sacos de $50 \mathrm{~kg}$ e levado para Laboratório de Recuperação de Áreas Degradadas da UFVJM para separação, identificação e análise.

\section{Análises físicas, químicas e mineralógicas}

As análises físicas do material foram realizadas no Laboratório de Mecânica e Física do Solo do Departamento de Agronomia da UFVJM, utilizando os dois materiais (substrato 1 e 2). Foram avaliadas as seguintes características físicas: densidade (Ds), densidade de partícula (Dp), porosidade total (PT), macroporosidade (Ma), microporosiade (Mic), espaço de aeração (EA), água disponível (AD) e capacidade de retenção de água do substrato (CRA). Os substratos foram homogeneizados e passados em peneira de 7,93 $\mathrm{mm}$, antes de serem submetidos às análises físicas para retirar as partículas maiores.

A determinação da densidade do solo foi feita em amostras deformadas. Utilizou-se uma proveta de $500 \mathrm{~mL}$, que foi cheia com o material, tendo sido pesada a seguir, fazendo-se então a relação massa/volume.A Dp foi determinada medindose o volume ocupado por $20 \mathrm{~g}$ de material fino seco em estufa, usando-se álcool etílico absoluto como líquido penetrante e balão aferido de $50 \mathrm{~mL}$. AP foi obtida pelo método indireto. Os cálculos foram obtidos através da fórmula: $D p=a /(50-b)$, em que a é o peso da amostra seca a $105^{\circ} \mathrm{C}$ e b, o volume de álcool gasto (EMBRAPA, 1997).

Para a determinação da CRA, as amostras do material foram acondicionadas em cilindros de PVC de $18,85 \mathrm{~cm}^{3}$, calculando a massa com base na densidade. Estes tiveram as bases forradas com tecidos de Nylon presas por um elástico de borracha. Todo conjunto (PVC, Nylon e elástico de borracha) foi previamente pesado antes do acondicionamento das amostras para a obtenção da tara a ser descontada posteriormente. As amostras distribuídas nos cilindros de PVC foram colocadas em bandejas e saturadas até dois terços da altura do recipiente por 24 horas. Depois, foram retiradas da bandeja e pesadas obtendo-se neste momento 
o volume de água correspondente a umidade de saturação da amostra ( $0 \mathrm{kPa})$ que equivale a porosidade total.

$\mathrm{Na}$ sequência, os cilindros foram mantidos na mesa de tensão sob a tensão de $1 \mathrm{kPa}$ e após alcançar a estabilidade, as amostras foram retiradas, pesadas e saturadas para acondicionamento sob a tensão de $2 \mathrm{kPa}$. Os mesmos procedimentos foram realizados as tensões de 6 e $10 \mathrm{kPa}$. Em seguida, as amostras foram levadas para a estufa a $105^{\circ} \mathrm{C}$ onde permaneceram até obtenção do peso constante para a determinação dos conteúdos de água. Obtida a curva, foram calculadas a PT, EA, AD, AR e a CRA segundo os parâmetros adotados por De Boodt e Verdonck (1972) e Wilson (1983).

Para a determinação da granulometria, foi utilizado o método da pipeta, com dispersão em $\mathrm{NaOH} 0,5 \mathrm{~N}$ e agitação mecânica (EMBRAPA, 1997). As frações areia fina e areia grossa foram separadas por peneiramento e as frações silte e argila por meio da sedimentação das partículas na suspensão já dispersada e estabilizada. De acordo com a lei de Stokes, diferentes tempos de sedimentação e diferentes alturas de suspensão do solo são considerados para separar argila mais silte e, depois argila. Esta coleta adicional da suspensão (fração silte + fração argila) incrementa a exatidão da determinação (RUIZ, 2005). A capacidade de campo foi determinada pelo método da coluna transparente (FERNANDES \& SYKES, 1968).

As análises químicas foram realizadas no laboratório de Fertilidade e Análise de Solo na UFVJM. Para determinar o pH, empregou-se a relação 1:2,5 de material: água (DEFELIPO ; RIBEIRO, 1997). Na determinação de $\mathrm{Ca}^{2+}, \mathrm{Mg}^{2+}$ e $\mathrm{Al}^{3+}(\mathrm{KCl} 1$ $\mathrm{N}$ ); $\mathrm{K}^{+}$e $\mathrm{H}+\mathrm{Al}$ (Acetato de Cálcio $1 \mathrm{~N} \mathrm{pH} \mathrm{7,0);} \mathrm{P,} \mathrm{Fe,} \mathrm{Mn,} \mathrm{Zn,} \mathrm{Cu} \mathrm{e} \mathrm{Pb}\left(\right.$ Mehlich $^{-1}$ ), utilizou-se a metodologia proposta pela Embrapa (1997).

Para a análise mineralógica dos substratos foram coletadas amostras de rochas e saprólitos presentes na área. A mineralogia quantitativa dos saprolitos e rochas foi avaliada por meio de influorescência de raio X, modelo EDX-720, com função Quick \& Easy Air-metal.

\section{RESULTADOS E DISCUSSÃO}

Os atributos físicos e químicos dos substratos estão apresentados nos tabelas 1 e 2. Na tabela 1, a composição granulométrica dos materiais excede $50 \%$ de areia do total do substrato. Isto ficou comprovado pela baixa capacidade destes substratos em reter água, conforme mostrado pela baixa capacidade de retenção de água e a capacidade de campo apresentados na tabela 1. As porcentagens de silte maiores que 20 dag $^{*} \mathrm{~kg}^{-1}$ podem dificultar o estabelecimento das plantas. A infiltração da água no material é rápida e quando se faz a irrigação, pode ocorrer a formação de uma crosta na superfície ocasionando direcionamento da água e erosão. Isto ocorre devido a porcentagem de silte de 30 a $40 \%$ presente em ambos materiais (DIAS et al., 2006).

Os teores de argila são baixos e tem-se uma CTC (capacidade de troca de cátions) considerada baixa tanto para o sustrato 2 quanto para o substrato 1, sendo necessário melhor manejo destes substratos, pois estes apresentam baixa capacidade química de sustentar uma vegetação. A baixa CTC está ligada a baixa retenção de cátions básicos no complexo de troca e consequentemente, problemas nutricionais para as plantas, sendo necessário elevar o teor de carbono orgânico nestes substratos (DIAS et al., 2006), com implemento de alguma técnica como transposição de topsoil, adubação de cobertura ou aplicação de mulch para elevar o teor de matéria orgânica. 
Estes dados de análise química de substrato estão de acordo com trabalho de Nunes e Filho (2013), em que o substrato apresentou uma textura franco arenosa, apresentado elevados percentuais de areia fina, o que pode incorrer em adensamento da camada superficial, diminuindo a infiltração da água e tende a aumentar a temperatura do substrato pela absorção de calor assim inibindo a germinação de plantas e crescimento de plântulas mais sensíveis.

Deve-se ressaltar que os valores de argila podem estar subestimados e os de silte e areia superestimados, já que a análise granulométrica foi a mesma usada para solos. Donaemmna (2003), tem demonstrado este problema em Latossolos ricos em óxidos de ferro, onde há uma necessidade de completa dispersão do material, que é dependente de tratamentos para reduzir a quantidade de silte e areia nas amostras. Vale ressaltar que estas análises físicas foram originalmente desenvolvidas para solos agrícolas e não para rejeitos de mineração, mas devido a inexistência atual de métodos específicos para caracterizar esses materiais, os resultados servem como referencial.

De acordo com a classificação na Quinta Aproximação para Análise de Solos em Minas Gerais com análise química Melich-1, os substratos apresentaram valores de $\mathrm{pH}$ considerados "bons" para estabelecimento de plantas (tabela 2), o que traz benefícios para uso destes em área de restauração, pois não necessita de correção para suprir a demanda de nutrientes para as plantas.

Os materiais são pobres em $\mathrm{Ca}^{+2}, \mathrm{Mg}^{+2} \mathrm{e} \mathrm{K} \mathrm{K}^{+}$, sendo necessário a correção química dos substratos, para que haja um desenvolvimento satisfatório das plantas sobre o mesmo (Tabela 2). Este fato foi observado no trabalho desenvolvido para análises de substratos advindo de mineração de ferro em Mariana- MG (DIAS et al., 2006) e também, para análises físicas e químicas de lavras a céu aberto em São Luis, MA (NUNES ; FILHO, 2013).

TABELA 1: Características físicas dos substratos 1 e 2. provenientes de uma extração de ferro em Conceição do Mato - MG

\begin{tabular}{lcc} 
& Substrato 1 & Substrato 2 \\
\hline Areia Grossa $\left(\mathrm{dag} / \mathrm{kg}^{-1}\right)$ & 19,9 & 21,6 \\
Areia Fina $\left(\mathrm{dag} / \mathrm{kg}^{-1}\right)$ & 46,5 & 50,6 \\
Silte $\left(\mathrm{dag} / \mathrm{kg}^{-1}\right)$ & 29,9 & 22,3 \\
Argila $\left(\mathrm{dag} / \mathrm{kg}^{-1}\right)$ & 3,5 & 5,3 \\
Substrato $\left(\mathrm{g} / \mathrm{cm}^{3}\right)$ & 2 & 1,4 \\
Partículas $\left(\mathrm{g} / \mathrm{cm}^{3}\right)$ & 2,8 & 2,6 \\
Macroporosidade (\%) & 40,9 & 42 \\
Microporosidade(\%) & 14,9 & 17,5 \\
Porosidade Total(\%) & 55,9 & 59,6 \\
Água Disponível & 5,9 & 6 \\
Espaço de Aeração(\%) & 10,1 & 12,4 \\
Capacidade de Retenção de água(\%) & 43 & 45,1 \\
Capacidade de Campo (60\%) & 21,3 & 33,6 \\
\hline
\end{tabular}

A densidade de partícula (Tabela 2) foi maior do que normalmente é observada em solos minerais, valores entre $1^{*} \mathrm{~cm}^{-3}$ a $1,4^{*} . \mathrm{cm} 3$. Geralmente, os AGRARIAN ACADEMY, Centro Científico Conhecer - Goiânia, v.4, n.8; p. 98 2017 
valores de densidade de partículas para latossolos está entre $1,4 \mathrm{~g} / \mathrm{cm}^{-3}$ em menores profundidades e 0,97g. $\mathrm{cm}^{-}{ }^{3}$ em maiores profundidades (DIAS et al, 2006).

Os substratos estudados apresentaram densidade maior do que os valores encontrados em outros solos, como neosolo e latossolos devido a presença de minerais de elevada densidade. Estes minerais pesados são constituídos principalmente por óxidos de ferro, como a hematita, cuja densidade é de $5,26 \mathrm{~g}^{\star} \mathrm{cm}^{-}$ ${ }^{3}$ e ainda a goethita, com 4,26 $\mathrm{gcm}^{-3}$ (DIAS et al., 2006). Estes valores são considerados de risco para atividades antrópicas, pois densidades de latossolo com valores acima de $3 \mathrm{~g}^{*} \mathrm{~cm}^{-3}$ podem ocasionar selamento superficial e dificuldades para o desenvolvimento de plantas devido a compactação (TORRES ; SARAIVA, 1997).

Os teores de $\mathrm{P}$ (Tabela 2) foram baixos nos dois tipos de substratos analisados, devendo ser adicionado fosfatos para garantir desenvolvimento satisfatório das plantas durante a revegetação. Estes baixos teores devem estar relacionados a fixação do fósforo por cargas positivas de óxidos e hidróxidos de ferro e alumínio (DIAS et al., 2006).

TABELA 2: Características químicas dos substratos 1 e 2, provenientes de uma extração de ferro em Conceição do Mato Dentro - MG.

\begin{tabular}{lcc}
\hline & Substrato 1 & Substrato 2 \\
\hline $\mathrm{pH}$ & 5,6 & 5,5 \\
$\mathrm{Ca}^{+2}\left(\mathrm{Cmol}_{\mathrm{c}} \mathrm{dm}^{-3}\right)$ & 0,2 & 0,1 \\
$\mathrm{Mg}^{+2}\left(\mathrm{Cmol}_{\mathrm{c}} \mathrm{dm}^{-3}\right)$ & 0,1 & 0,1 \\
$\mathrm{Al}^{+3}\left(\mathrm{Cmol}_{\mathrm{c}} \mathrm{dm}^{-3}\right)$ & 0,1 & 0,2 \\
$\mathrm{H}+\mathrm{Al}\left(\mathrm{Cmol}_{\mathrm{c}} \mathrm{dm}^{-3}\right)$ & 1,6 & 1,3 \\
$\mathrm{~T}\left(\mathrm{Cmol}_{\mathrm{c}} \mathrm{dm}^{-3}\right)$ & 2 & 1,5 \\
$\mathrm{SB}\left(\mathrm{Cmol}_{\mathrm{c}} \mathrm{dm}^{-3}\right)$ & 0,4 & 0,2 \\
$\mathrm{t}(\%)$ & 0,5 & 0,4 \\
$\mathrm{~m}(\%)$ & 29,6 & 54,3 \\
$\mathrm{MO}(\%)$ & 0,1 & 0,1 \\
$\mathrm{~V}(\%)$ & 19,6 & 14,6 \\
$\mathrm{P}\left(\mathrm{mg} / \mathrm{dm}^{-3}\right)$ & 0,6 & 2,3 \\
$\mathrm{Fe}\left(\mathrm{mg} / \mathrm{dm}^{-3}\right)$ & 146,6 & 119,1 \\
$\mathrm{Zn}\left(\mathrm{mg} / \mathrm{dm}^{-3}\right)$ & 0,2 & 0,2 \\
$\mathrm{Cu}\left(\mathrm{mg} / \mathrm{dm}^{-3}\right)$ & 1 & 1 \\
$\mathrm{Mn}\left(\mathrm{mg} / \mathrm{dm}^{-3}\right)$ & 1,4 & 8,1 \\
$\mathrm{Ba}\left(\mathrm{mg} / \mathrm{dm}^{-3}\right)$ & 0,3 & 0,1 \\
$\mathrm{~K}\left(\mathrm{mg} / \mathrm{dm}^{-3}\right)$ & 2,7 & 8,2 \\
$\mathrm{~S}\left(\mathrm{mg} / \mathrm{dm}^{-3}\right)$ & 0 & 0 \\
\hline
\end{tabular}

Os teores de alumínio em ambos os substratos foram baixos, isto se deve principalmente ao tipo de rocha que está presente na pedogênese no solo, tais como saprolitos de vermiculita e rochas de quartzo. Isto ainda favorece o estabelecimento de espécies vegetais por não causar impedimento químico no crescimento de raízes pelo alumínio. Em contrapartida apresenta-se uma soma de bases e saturação por bases com teores muito baixos, o que indica que o material apresenta-se inerte e necessita de correção para dar suporte a vegetação.

Os teores de $\mathrm{Zn}$, e $\mathrm{Mn}$ dos substratos também foram baixos. Os valores de $\mathrm{Cu}$ foram médios e o Fe apresentou valor elevado. Assim, conclui-se que a adição 
de fontes de nutrientes em rejeitos de mineração deve ser aplicada para o desenvolvimento das plantas no processo de revegetação, seja em fontes orgânicas (TRINDADE et al., 1997) ou mineral, devido a pobreza de nutrientes dos substratos (DIAS et al., 2006). Em trabalho, avaliando os impactos de mineração a céu aberto Nunes e Filho (2013) identificaram a baixa fertilidade do substrato como um fator predominante em áreas mineradas devido ao tipo de revolvimento de solo. Assim valores baixos de características químicas do solo são esperados.

Verifica-se na figura 1, que os dois substratos são compostos predominantemente por granulometria menor de $4 \mathrm{~mm}$, ou seja, compõem-se de um material particulado e pequeno. O material apresenta de 5 a $10 \%$ de torrões e partes maiores como calhaus (Figura 1). Enquanto a maior parte dos substratos estão concentradas nas partes mais finas como areia fina, até $60 \%$ em ambos substratos.

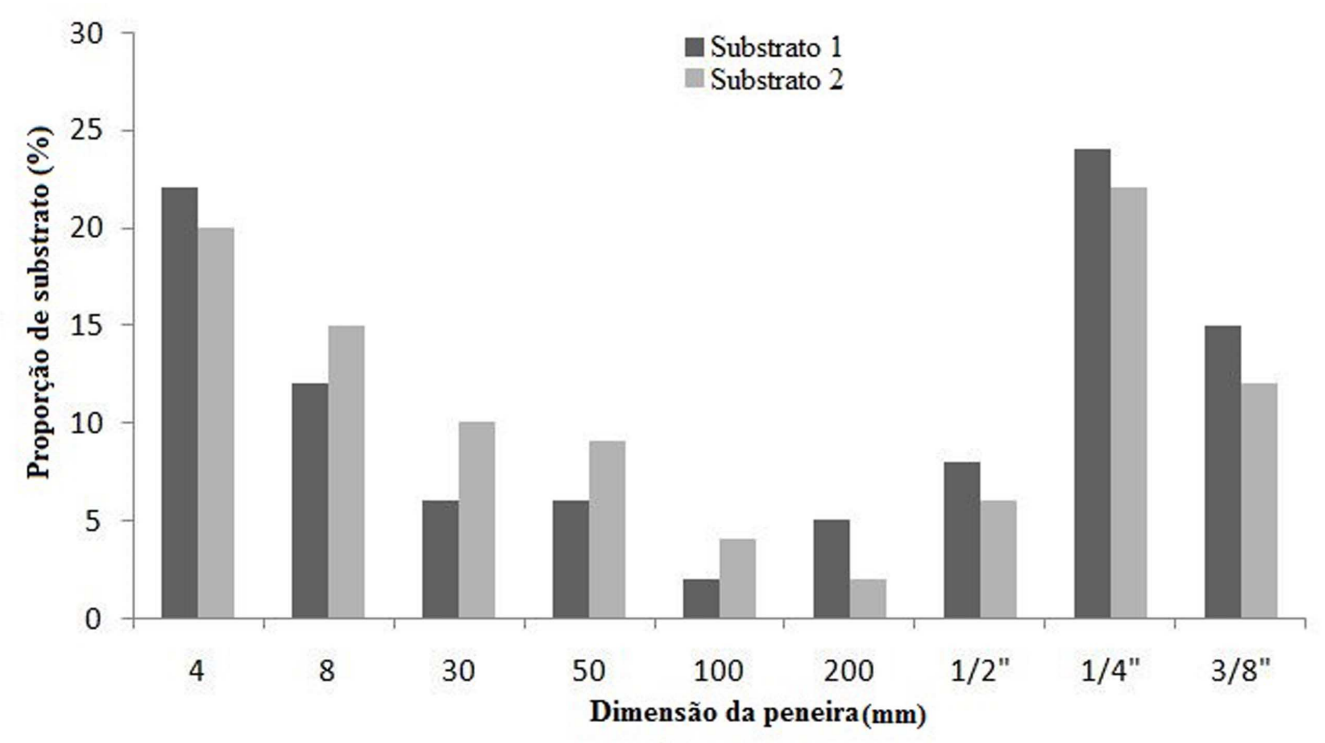

FIGURA 1 Separação granulométrica por peneiras em dois substratos provenientes da mineração de ferro em Conceição do Mato Dentro - MG.

Os saprolitos e rochas observadas nos dois substratos foram biotita xisto, vermiculita xisto 1, vermiculita xisto 2, petroplintita e quartzo (Tabelas 3 e 4). Os teores de ferro foram altos nos substratos (Tabelas 2 e 3), o que pode indicar problemas na revegetação dessas áreas, pois alguns elementos, em pequenas concentrações, são nutrientes essenciais ao desenvolvimento das plantas, entretanto em concentrações excessivas resultam em fito-toxidez (DING et al., 2007). Elevado teor de ferro é o resultado do processo de formação dos substratos advindos das rochas, que em sua maioria apresentaram ferro na composição (Tabela 3).

Pelo teste de correlação, percebe-se que o substrato 2 sofre influência das vermiculitas xisto 1 e 2 como também do quartzo. Tal fato explica a composição de elevados teores de silício. Já o substrato 1 apresenta-se correlacionado com todos os tipos de saprolitos/rochas presentes na área. Ou seja, os elevados teores de ferro estão relacionados a presença de petroplintita na área assim como a baixa fertilidade associada aos quartizitos. 
TABELA 3: Teores médios de elementos em saprolitos e rochas encontrados em

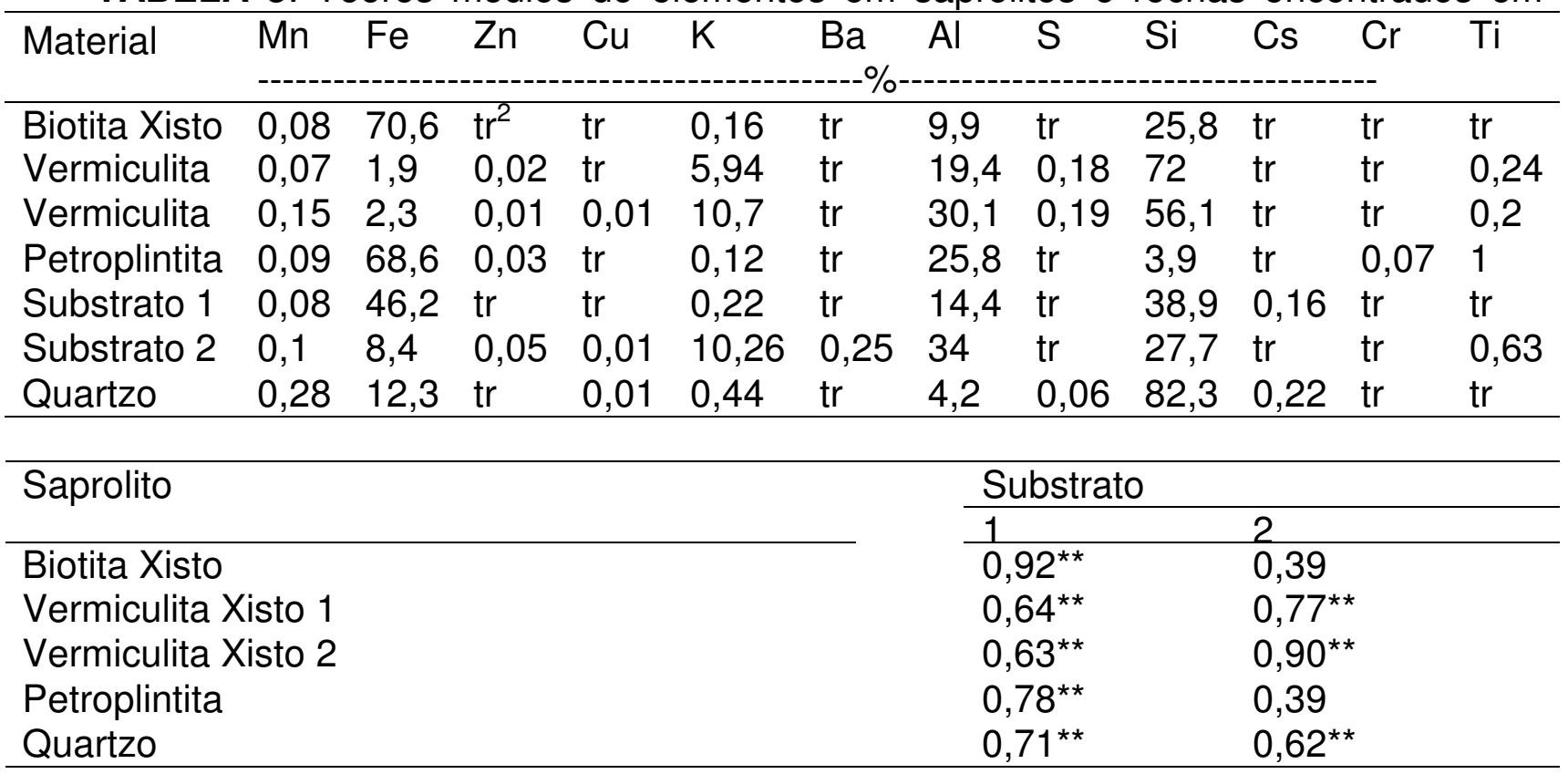

**: Representam testes com correlação significativa positiva a 95\% de confiança.

\section{CONCLUSÃO}

Os substratos apresentam baixa capacidade de retenção de água e são propensos ao selamento superficial devido a quantidade de silte presente. As análises químicas indicaram que há necessidade de correção dos substratos, pois possuem baixos teores de macronutrientes e elevados teores de ferro, que são oriundos das rochas de origem, havendo necessidade de corretivos e adubos para promover desenvolvimento inicial de mudas no estabelecimento da vegetação.

\section{REFERÊNCIAS}

DE BOODT, M.; VERDONCK O. The physical properties of the substrates in horticulture. Acta Horticulturae, v.26, n.2, p. 37 - 44,1972 . http://dx.doi.org/10.17660/ActaHortic.1972.26.5 >.

DEFELIPO, B.V. \& RIBEIRO, A.C. Análise química de solo (metodologia). Boletim de Extensão, v.29, n.2, 1-26, 1997.

DIAS G.P., FONTES M.P.F, COSTA L.M., BARROS N.F. Caracterização química, física e mineralógica de estéreis de rejeito da mineração de ferro da mina de Alegria, Mariana- MG. Revista Pesquisa Agropecuária Tropical, v.36, n.1, p. 45-52, 2006. < http://revistas.ufg.emnuvens.com.br/pat/article/view/2171/2119>12 Nov. 2015.

DING, B; SHI, G.; XU, Y.; HU, J.; XU, Q. Physiological responses of Alternanthera philoxeroids (Mart) Griseb leaves to cadmium stress. Environmental Pollution, v. 147, p.800-803, 2007. < doi:10.1016/j.envpol.2006.10.016>.

DONAGEMMA, G. K. H. A.; RUIZ, M. P. F.; FONTES, J. C. KER \& C. E. G. R. SCHAEFER. Dispersão de Latossolos em resposta à utilização de pré-tratamentos na análise textural. Revista Brasileira Ciência do Solo, Viçosa, v.27, n,4, p.765772. 2003. 
EMBRAPA - Empresa Brasileira De Pesquisa agropecuária. Manual de métodos de análise de solo. Segunda edição. Rio de Janeiro: Ministério da Agricultura e do Abastecimento, 1997.<https://www.agencia.cnptia.embrapa.br/Repositorio/Manual+d e+Metodos_000fzvhotqk02wx5ok0q43a0ram31wtr.pdf > 07 Jul 2015.

FELFILI , J.M.; FAGG C.W.; LINDOSO, G.S. Bases florísticas para a recuperação de áreas degradadas na bacia do São Francisco no bioma cerrado. In: Felfili, JM, Sampaio JC, Correia RMAC, editores. Bases para recuperação de áreas degradadas na bacia do São Francisco. Brasília; 2008.

FERREIRA, G.L.B.V. Meio ambiente e mineração na Constituição Federal. Cadernos de Direito, v.11(20): p.111-124, 2011.

FERNANDES, B.; SYKES, D.J. Capacidade de campo e a retenção de água em três solos de Minas Gerais. Revista Ceres, v.15, n.1, p.1-39, 1968.

FIGUEIREDO, P.H.A.; MIRANDO, C.C; MATEUS, F.A.; VALCACEL, R. Avaliação do potencial seminal da Cecropia Pachystachya Trécul no banco de sementes do solo de um fragmento florestal em restauração espontânea na Mata Atlântica, Pinheiral RJ. Revista de Biociências da Universidade de Taubaté, v.17, n.2, 2011. < http://www.ufrrj.br/institutos/if//mbh/pdf/publica\%C3\%A7ao_revista/revista21.pdf> 04 Set 2015.

GOMES, M. A.; PEREIRA, C. Al. PERES, A. E. C. Caracterização tecnológica de rejeito de minério de ferro. REM: Revista Escola de Minas, v. 64, n.2, p. 233-236, 2011.

MIRANDA NETO, A.; MARTINS, S. V.; SILVA, K. A.; GLERIANI, J. M. Estrato de regeneração natural de uma floresta restaurada com 40 anos. Pesquisa Florestal Brasileira, v. 32, n. 72, p. 409 - 420, 2012 < Estrato de regeneração natural de uma floresta restaurada com 40 anos.>.

NUNES, Z.M.; FILHO, M.S.F. Impactos da mineração sobre as funções e os atributos químicos e físicos do solo - o caso da comunidade Taim em São Luis, MA. In: Anais do XIV Encuentro de geógrafos de America Latina; 2013; Peru; 2013 p.231.

RUIZ, H.A. Incremento da exatidão da análise granulométrica do solo por meio da coleta da suspensão (silte + argila). Revista Brasileira de Ciência do Solo, v.29, n.2, p. 297-300, 2005. < http://www.scielo.br/pdf/rbcs/v29n2/24166.pdf> 14 Nov 2015.

SILVA, G.P; FONTES, M.P.F; COSTA, L.M; BARROS, N.F. Caracterização química, física e mineralógica de estéreis e rejeito da mineração de ferro da mina de Alegria, Mariana - MG. Revista Pesquisa Agropecuária Tropical, v.36, n.1, p.45-52, 2006. < http://revistas.ufg.emnuvens.com.br/pat/article/view/2171/2119> 10 Dez 2015.

SILVA, A.C.; CAVALCANTE, L.C.D.; FABRIS, J.D.; JUNIOR, R.F.; BARRAL, U.M.; FARNEZI, M.M.M.; VIANA, A.J.S.; ARDISSON, J.D.; FERNANDEZ-OUTON, L.E.; 
LARA, L.R.S.; STUMPF, H.O.; BARBOSA, J.B.S.; DA SILVA, L.C. Chemical, mineralogical and physical characteristics of a material accumulated on the river margin from mud flowing from the collapse of the iron ore tailings dam in Bento Rodrigues, Minas Gerais, Brazil. Revista Espinhaço, v.5(2), 44-53, 2016.

TORRES, E.; SARAIVA, O.F. Camadas de impedimento mecânico do solo em sistemas agrícolas com a soja. Londrina: Embrapa Soja, p.58 (Embrapa Soja Circular Técnica), 1997.<https://www.agencia.cnptia.embrapa.br/Repositorio/circTec23_000g39z6vqc0 2wx5ok0r2ma0n1tmj3sg.pdf> 12 Nov 2015.

TRINDADE, A.V; DIAS, A.C.P; JUCKSCH, I. Efeito de resíduos urbanos e de fungos micorrízicos arbusculares no crescimento de capim gordura Melinis minutiflora e cedro Cedrela fissilis em rejeito de mineração. Revista Árvore, v.21, n.4, p.575-582, 1997. < http://coral.ufsm.br/cienciaflorestal/artigos/v9n1/art7v9n1.pdf> 10 Dez 2015.

WILSON CGS. Tomato production in bark substrates. Acta Horticultura, v.150, n.4, p. 271-276, 1983. < http://dx.doi.org/10.17660/ActaHortic.1986.17>.

VIANA, I.R.; BORGES, M.S.; CARDOSO, P.S. Estratégias de restauração química em ambientes alterados: uma revisão. Revista Iniciação Científica, v.10, n.1, 2012. 